\title{
MOIST VAGINAL PACKING FOR UTERO-VAGINAL PROLAPSE-A CLINICAL STUDY
}

Manidip Pal, Soma Bandyopadhyay

1. Associate Professor, Department of Obestetrics \& Gynaecology, College of Medicine \& JNM Hospital, WBUHS, Kalyani, Nadia, West Bengal.

2. Associate Professor, Department of Obestetrics \& Gynaecology, Jawaharlal Nehru Institute of Medical Sciences, Porompat, Imphal, Manipur.

\section{CORRESPONDING AUTHOR}

Manidip Pal,

Associate Professor, OBGYN,

College of Medicine \& JNM Hospital,

WBUHS, Kalyani, Nadia,

West Bengal, PIN -741235.

E-mail: manideep2b@yahoo.com

Ph: 00919051678490

ABSTRACT: BACKGROUND: Utero-vaginal prolapse is a common condition in aged women and often they come to us with decubitus ulcer. Prolonged vaginal packing not only will heal the decubitus ulcer but also it may help in returning the normal rugosity of the vaginal skin.AIMS: To assess the role of prolonged moist vaginal packing in utero-vaginal prolpase. SETTINGS \& DESIGN: It was an OPD based prospective study conducted at the gynecology OPD of College of Medicine \& JNM Hospital, WBUHS, Kalyani, Nadia, West Bengal and Jawaharlal Nehru Institute of Medical Sciences, Porompat, Imphal, Manipur. METHODS \& MATERIAL: Hundred (100) patients of utero-vaginal prolapse with decubitus ulcer were studied. After initial staging (POPQ staging), daily moist (5\% povidone-iodine solution soaked gauze) vaginal packing at home was advised. After 2 weeks, re-examination done for decubitus ulcer healing. Packing continued till operation (interval 1- 11/2 month). Preoperative staging and modification of operation were noted. On follow up complication (mainly recurrence) was noted. RESULTS: Initial staging was stage 3 - 39\%, stage 4 - 61\%. Preoperative scoring revealed stage 3 became stage 2 in $54 \%$ cases and stage 4 became stage 3 in $49 \%$ cases. This improvement helped us to avoid excessive excision of vaginal mucosa. CONCLUSION: Prolonged pre-operative moist gauze vaginal packing may improve the outcome of the disease.

KEY WORDS: Utero-vaginal prolapse, decubitus ulcer, povidone-iodine

INTRODUCTION: Utero-vaginal prolapse is a common complaint of elderly women in gynecology ${ }^{1}$ and there is roughly a doubling in the risk of prolapse with every completed decade of life. ${ }^{2,3}$ Often these patients report late with decubitus ulcer. This is an ulcer due to the venous congestion - a frequent associated finding of long standing prolapse. The treatment of decubitus ulcer is repositioning of the vagina by packing. While doing so incidentally it was found that vaginal packing improves the staging of prolapse. This incidental finding leads us to check this matter to the subsequent cases.

MATERIALS \& METHODS: One hundred patients of utero-vaginal prolapse with decubitus ulcer were studied. Staging was done by POP-Q (Pelvic organ prolapse quantification) system. They were treated by $5 \%$ povidone-iodine solution soaked vaginal packing which was replaced every 
day with new one and also anytime if it had fallen out. Except few admitted cases, most of the patients were treated on OPD (outpatient department) basis due to the huge OPD patient load and lack of indoor bed strength in comparison to that. Informed consent was obtained from all patients. Patients were taught the technique of povidone-iodine soaked vaginal gauze packing and they followed the advice at home. They replaced the pack every day with new one and also any other time whenever it came out. Re-examination was done after 2 weeks. Most of the decubitus ulcers got healed by that time, but they could not be operated at that time. Operation dates usually could be given after $1-1 \frac{1}{2}$ months. They were asked to continue the povidoneiodine soaked vaginal gauze packing. Before the operation, staging of the prolapse was assessed again.

OBSERVATIONS: Patients were aged in between 50 - 70 years, highest no. in (56-60) years group 44\%, followed by (61-65) years group 37\%. Para $2 \& 3$ constituted the majority (83\%). Regarding duration of prolapse, highest number was observed in 10-15 years group (35\%), next it was 5-10 years group (32\%). (Table 1)

Degree of prolapse was assessed by POP-Q system. In first visit, before starting of vaginal packing, stage 3 was 39\%, stage 4 was $61 \%$. Reassessment before operation (gap is between 1 - $1 \frac{1}{2}$ months) revealed the improvement as - stage $3 \rightarrow$ stage 2 (54\%), stage $4 \rightarrow$ stage $3(49 \%)$. (Table 2) It is worthy to mention over here that this improvement in degree of prolapse was relative improvement. Patients were asked to strain to increase intra-abdominal pressure and the degree of prolapse was assessed before operation in the ward - improvement noted. But whenever the cervix was grasped by vulsellum and pulled out during operation, then the improvement in degree of prolapse was not so noticed, though the POP-Q classification does not change because of this maneuver. Age, parity and duration of prolapse in relation to the improvement is described in table no 3.

Though these improvements are not statistically significant, but it helped us 'not to do excessive excision of vaginal mucosa'.

On follow up, no patient had dyspareunia. Only one patient had recurrent cystocele, rest all are doing well.

DISCUSSION: Decubitus ulcer results due to venous congestion. Venous congestion causes edema of the local tissue which may cause decrease in tissue strength. Prolong packing relieves venous congestion, resulting in healing of decubitus ulcer ${ }^{4}$ and disappearance of local tissue oedema. All these may increase the strength of the vaginal tissue.

A patient with decubitus ulcers who received prolong wound care with povidone iodine soaked gauze developed hypernatremia, hyperchloremia, metabolic acidosis and renal failure ${ }^{5}$ In present study we didn't encounter such like problem may be because decubitus ulcer was healed by the initial 2 weeks of vaginal packing, so there was no raw area for increase absorption of iodine.

The improvement in degree of prolapse apparently does not seem to be a significant finding. But it helped us in managing these patients in following way - less excision of vaginal mucosa; as the present concept of prolapse surgery is to avoid excessive excision of vaginal mucosa thus preventing disfigurement of vagina.

In the article of "management of iatrogenic vaginal stenosis" authors opines that - some surgeons elect to routinely perform anterior and posterior colporrhaphies together, regardless of the fact that only the anterior or the posterior compartment is lacking support. One must be 
cautioned against attempting to improve support where no such improvement is needed. Such practice increases the risk of excising too much mucosa or over-aggressively plicating the vaginal subepithelium and ultimately leading to vaginal stenosis. ${ }^{6}$

The goal of surgery is relief of prolapse symptoms and overcorrection must be avoided. ${ }^{7}$ Anterior colporrhaphy, the most commonly performed prolapse repair, may narrow the vagina from a too wide excision of vaginal mucosa. Posterior colpoperineorrhaphy has been the major cause of vaginal stenosis after prolapse repair. In anticipation of continuing postmenopausal atrophy, undue tightening of the vagina should be avoided. ${ }^{8}$ The rate of de novo dyspareunia was $16 \%$ after anterior colporrhaphy. ${ }^{9}$ Hence by doing less excision of vaginal mucosa these discomforts of the patient could have been avoided. In fact no patient complained of dyspareunia on follow up.

Next thing of concern to us was recurrence of pelvic organ prolapse. Patients were in follow up for last 3 years and surprising to us, except one case of recurrence of cystocele, no other complication was detected.

In a resource poor country like India where many poor patients have to wait long time due to the busy operative schedule of the govt. hospitals, instead of wasting this unnecessary time, this simple procedure can bring back their vaginal texture and help the surgeon to do less excision of vaginal mucosa. This can reduce the postoperative morbidity and improve the quality of conjugal life, especially in younger patients.

How does these packing improved the degree of prolapse in some patients is a great question. May be if we can do the morphological and biochemical analysis of the vaginal wall of the different subsets of the patients and compare them with the control - an answer could be found. But we don't have such facilities in our set up.

There are two shortfalls of the present study. One is that there was no control group. Second one is that the end of the vaginal packing could not be pinpointed to either 1 month or $1 \frac{1}{2}$ months due to the constrain of our OT date schedule.

CONCLUSION: Vaginal packing is an age old method for the treatment for decubitus ulcer in utero-vaginal prolapse. Usually packing is done till the healing of the ulcer and decubitus ulcer normally get healed by 10-14 days. The new finding in this study is that, prolonged packing can change the scenario little bit. Hence we conclude that, prolonged pre-operative moist gauze vaginal packing (in this study $5 \%$ povidone-iodine soaked gauze) after reduction of the uterovaginal prolapse may improve the postoperative outcome of the disease.

ACKNOWLEDGEMENT: We would like to express our sincere thanks and gratitude to the Principal and Medical Superintendent of College of Medicine \& JNM Hospital, WBUHS, Kalyani and Director and Medical Superintendent of Jawaharlal Nehru Institute of Medical Sciences, Imphal for allowing us to do the study and publish the work.

\section{REFERENCES:}

1. Padubidri VG, Daftary SN. Genital prolapsed. In: Howkins and Bourne Shaw's Textbook of Gynaecology, 14th edn New Delhi: Elsevier 2008, 298-309.

2. Swift S, Woodman P, O'Boyle A, Kahn M, Valley M, Bland D, Wang W, Schaffer J. Pelvic Organ Support Study (POSST): the distribution, clinical definition, and epidemiologic condition of pelvic organ support defect. Am J Obstet Gynecol 2005; 192:795-806. 
3. Swift S. Classification and epidemiology of pelvic organ prolapse. In: Cardozo L, Staskin D (ed.) Textbook of Female Urology and Urogynecology $2^{\text {nd }}$ edn Oxon: Informa Healthcare 2006, 999-1008.

4. Gad N. The use of triple vaginal ring pessaries in procidentia prior to total Prolift procedure. Pelviperineology 2007, 26: 93-94.

5. Paul MW. Antiseptics, disinfectants and sterilants. In: Goldfrank LR, Flomenbaum N, Hoffman RS, Howland MA, Lewin NA, Nelson LS. (ed.) Goldfrank's toxicologic emergencies, $8^{\text {th }}$ edn McGraw-Hill, 2006: 1387.

6. Vassallo BJ, Karram MM. Management of iatrogenic vaginal constriction. Obstet Gynecol 2003; 101:512-20.

7. Grimes CL, Shippey S. Urogynecology and reconstructive pelvic surgery. In: Hurt KJ, Guile MW, Bienstock JL, Fox HE, Wallach EE (ed.) The John Hopkins manual of gynecology and obstetrics, $4^{\text {th }}$ edn New Delhi: Lippincott Williams \& Wilkins 2011, 365381.

8. Amias AG. Sexual life after gynaecological operations - II. Br Med J 1975, 2: 680-81.

9. Nguyen JN, Burchette RJ. Outcome after anterior vaginal prolapsed repair: a randomized controlled trial. Obstet Gynecol 2008, 111: 891-98.

TABLE 1

Age, Parity \& Duration of Prolapse

\begin{tabular}{|l|l|l|l|l|l|}
\hline Age (years) & No. & Para & No. & Duration of prolapse & No. \\
\hline$<50$ & 4 & P 1 & 2 & $<5$ years & 22 \\
\hline $50-55$ & 11 & P 2 & 38 & $5-10$ years & 32 \\
\hline $56-60$ & 44 & P 3 & 45 & 10 -15 years & 35 \\
\hline $61-65$ & 37 & P 4 & 10 & $>15$ years & 11 \\
\hline $66-70$ & 4 & P 5 & 5 & & 100 \\
\hline Total & 100 & & 100 & & \\
\hline
\end{tabular}

TABLE 2

DEGREE OF PROLAPSE

\begin{tabular}{|l|l|l|l|l|}
\hline \multicolumn{4}{|l|}{ BEFORE VAGINAL PACKING } & After vaginal packing \\
\hline Stage 3 & 39 & Stage 2 & 21 & $\begin{array}{l}54 \% \\
(21 \text { out of 39) }\end{array}$ \\
\hline & & $\begin{array}{l}\text { No change i.e. remain in } \\
\text { stage 3 }\end{array}$ & 18 & $\begin{array}{l}46 \% \\
(18 \text { out of 39) }\end{array}$ \\
\hline Stage 4 & 61 & Total & 39 & $\begin{array}{l}3 \% \\
(2 \text { out of } 61)\end{array}$ \\
\hline & Stage 2 & 2 & $\begin{array}{l}49 \% \\
(30 \text { out of } 61)\end{array}$ \\
\hline & & Stage 3 & 30 & $\begin{array}{l}48 \% \\
(29 \text { out of } 61)\end{array}$ \\
\hline & $\begin{array}{l}\text { No change i.e. remain in } \\
\text { stage 4 }\end{array}$ & 29 & \\
\hline
\end{tabular}


ORIGINAL ARTICLE

TABLE 3 IMPROVEMENT OF DEGREE OF PROLAPSE

\begin{tabular}{|c|c|c|c|c|c|c|c|c|c|c|c|}
\hline \multicolumn{6}{|c|}{ Stage $3 \rightarrow$ Stage 2} & \multicolumn{6}{|c|}{ Stage $4 \rightarrow$ Stage 3} \\
\hline \multicolumn{2}{|c|}{ Age (years) } & \multicolumn{2}{|c|}{ Para } & \multicolumn{2}{|c|}{$\begin{array}{c}\text { Duration of } \\
\text { prolapse(years) }\end{array}$} & \multicolumn{2}{|c|}{ Age (years) } & \multicolumn{2}{|c|}{ Para } & \multicolumn{2}{|c|}{$\begin{array}{c}\text { Duration of } \\
\text { prolapse(years) }\end{array}$} \\
\hline$>50$ & 2 & P 1 & 1 & $<5$ & 12 & $>50$ & 0 & P 1 & 0 & $<5$ & 1 \\
\hline $50-55$ & 6 & P 2 & 16 & $5-10$ & 7 & \multirow{2}{*}{$\frac{50-55}{56-8}$} & 3 & P 2 & 7 & $5-10$ & 15 \\
\hline $56-60$ & 9 & P 3 & 4 & $10-15$ & 2 & & 17 & P 3 & 22 & $10-15$ & 12 \\
\hline $61-65$ & 4 & P 4 & 0 & $>15$ & 0 & $61-65$ & 10 & P 4 & 1 & $>15$ & 2 \\
\hline $66-70$ & 0 & P 5 & 0 & Total & 21 & $66-70$ & 0 & P 5 & 0 & Total & 30 \\
\hline \multirow[t]{5}{*}{ Total } & 21 & Total & 21 & & & To & 30 & Total & 30 & & \\
\hline & & & & & & \multicolumn{6}{|c|}{ Stage $4 \rightarrow$ Stage 2} \\
\hline & & & & & & & Age & \multicolumn{2}{|c|}{ Para } & \multicolumn{2}{|c|}{$\begin{array}{l}\text { Duration of } \\
\text { prolapse }\end{array}$} \\
\hline & & & & & & 1 & 58 & \multicolumn{2}{|c|}{ P 3} & \multicolumn{2}{|c|}{$<5$ years } \\
\hline & & & & & & 2 & 60 & & & $5-10$ & \\
\hline
\end{tabular}

